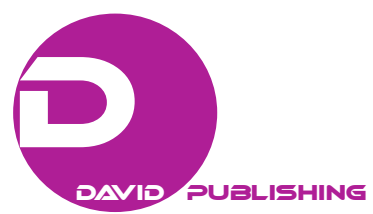

\title{
A Study on Crisis Management of Typhoon Hato in Macau
}

\author{
Chan Kin-Sun, ZHENG Zhong-xing, GONG Rui-lin \\ University of Macau, Macau, China
}

\begin{abstract}
Due to unusual climatic events, more and more strong typhoons (or hurricanes) appear, thus, governments have to formulate suitable crisis management for the visits of typhoons. Recently the visit of typhoon Hato has already caught public's attention on the effectiveness of Macau SAR Government's crisis management. The study bases on news coverage of typhoon Hato and the theoretical framework, derived from crisis stage theory and $4 \mathrm{R}$ model of crisis management, to review Macau's crisis management. Expectedly, Macau SAR Government is requested to strengthen corresponding infrastructure and collaboration with neighboring cities in crisis warning system. Senior management accountability and urban renewal policy are also demanded by Macau residents.
\end{abstract}

Keywords: crisis management, crisis stage, $4 \mathrm{R}$ theory of crisis management

\section{Introduction}

The recent years witnessed unusual climatic events like El Nino and reverse El Nino phenomena all around the world. These events all exert an effect on the number and intensity of typhoons (Zhang \& Zhao, 1992). In 2017, three typhoons hit Macau in August and particularly the damage caused by Typhoon Hato has relatively been rare in the past one decade (Lee, 2017). Likewise, the US was also hit by several super hurricanes, such as Hurricane Harvey, Jose, Elma, and Katia, which caused enormous losses in the stricken areas (WMO, 2018). In fact, it is not the first time the cyclone caused a great disaster. In 2005, targeted policies were formulated by the US government in the wake of Hurricane Katrina (Moynihan, 2009). While in Macau, corresponding measures were also implemented in 2008 after Typhoon Hagupit (Y. -D. Huang \& Z. -H. Huang, 2009). As a tourism city, Typhoon Hato not only caused a great loss to the personal and financial security of Macanese, which to some extent had a negative effect on Macau's image, but also posed a challenge to its crisis management.

\section{Literature Review}

This part will offer the definition of crisis, and then chart a course for crisis management theory in governance, and finally establish a theory framework for the study.

\section{Crisis}

"Crisis" refers to events causing severe threats to basic values of social systems and the structure of code of conduct, which must be dealt with by making decisions under a circumstance with high uncertainty in quite a

Chan Kin-Sun, Ph.D., Assistant Professor, Department of Government and Administration, University of Macau.

ZHENG Zhong-xing, Master of Public Administration, Graduate, Department of Government and Administration, University of Macau.

GONG Rui-lin, Student of Master of Public Administration, Master Student, Department of Government and Administration, University of Macau. 
short time (Xue, Zhang \& Zhong, 2003). Some scholars put forward "more study result on crisis will get along with more diversified perspectives on the study of crisis" (Zhang, 1992). Originally, "crisis" only stands for turning point or decisive moment. Then it evolves to be defined as "a period". During this "period", certain relations will be lifted and even changed by some conflicts resulting from them (Alastair, 1979). While for scholars in Mainland China, they raised the definition of crisis that it is an aggregation of negative scenarios with high uncertainty needing to be dealt with quickly when core values of decision-makers are seriously threatened or challenged with inadequate corresponding information (Zhang, 2003). Although theories raised by scholars may, to some extent, differ from each other, they are summed up by this study that crisis management should be defined as an emergency that will cause a great loss or threaten groups, and for the sake of reducing the loss to the minimum level, decision-makers need to make critical decisions in limited time under certain circumstance through effective means. In the meantime, crisis possesses five features as follows: (1) spontaneity and urgency; (2) objectivity and universality; (3) threat and damage; (4) uncertainty and dynamics; and (5) duality and manageability (Zhang, 2010).

\section{Crisis Management}

Studies on crisis management in the worldwide started at the beginning of 1960s and scholars all over the world offered different definitions on it. Jan Chung-Yuang brought up that crisis management was a dynamic scheming process (Jan, 2004). Studies done by Evans and Elphick were mainly about crisis management for terrorist attacks (Evans \& Elphick, 2005). De Sausmarez came up with corresponding measures in different stages of Asia-Pacific financial crisis (De Sausmarez, 2004). Seeger and Ulmer suggested effective crisis management were the aggregation of effective evaluation, response, and measures to ease and eliminate crisis (Seeger \& Ulmer, 2001). Fink proposed that effective crisis management could treat the root in different phases. If crisis could be found in time and be evaluated and prevented, the loss caused by it will be greatly reduced. However, the most effective period to handle crisis is its prodromal stage and the government needs to take different measures in different stages after the prodromal crisis stage (Fink, 1986). Now scholars from Mainland China integrate these proposes in an overall manner and sum it up as eight factors (Zhang, 2003): (1) political promise, leadership, and support; (2) comprehensive crisis management; (3) development approach of crisis management; (4) total process of crisis management; (5) total risks of crisis management; (6) integration of crisis management; (7) adequate resources supporting crisis management; and (8) performance of crisis management.

In conclusion, crisis management could be divided into two dimensions in terms of its definition, namely, stage theory and management theory.

\section{Crisis Stage Theory}

The life cycle of crisis will go through prodromal stage, acute stage, response stage and finally it is settled. In its life cycle, the hazards of crisis change constantly thus approaches to handle them are different. With this in mind, scholars have divided crisis into different stages for they think this is conducive to realize the specification of crisis management model, namely, crisis stage theory easily acceptable for the academic circle. Fink stated that the development of crisis theory was similar to that of diseases, which are both characterized by stages, thus medical vocabularies are used to define the four stages (Fink, 1987):

Prodromal crisis stage. This is the early-warming period of the appearance of crisis, when the omen of crisis can be often seen. If crisis in the stage can be appreciated as early as possible, crisis will be quite easier to handle. 
Acute crisis stage. This is the shortest stage among the four ones while its hazard is the biggest. Crisis will be exploded in this stage and spread fast. If appropriate approaches can be adopted in time, its hazard will be reduced to minimum. Otherwise, the consequences will be disastrous.

Response crisis stage. This stage aims to handle the crisis and it is the critical stage to turn the corner. But it is interacted with acute crisis stage closely, thus these two stages should be analyzed together.

Recovery stage. This stage focuses on self-review and self-analysis, which to the greatest extent avoid a repeat of crisis. It may possibly introduce a new long-term response mechanism. However, such mechanisms must be built upon consensus so this stage can continue indefinitely.

\section{R Model of Crisis Management}

4R theory of crisis management was proposed by Heath, namely, reduction, readiness, response, and recovery (Heath, 2001).

Reduction. It is the core content of crisis management. Since the reduction of risks, dilution and time saved enable decision-makers to reduce the probability of occurrence and loss caused by the crisis to the maximum level. Furthermore, the reduction strategy is mainly executed by subjects like people, system, structure, and environment.

Readiness. It is a supervisory control for specific environment, which is characterized by early warning and monitoring system. In doing so, it responds to the adverse development in all details and sends signals to other systems or those responsible.

Response. It refers to the management strategy when organizations or decision-makers deal with crises. It is widely believed that there are four steps of the response crisis management, namely, identifying crises, isolating them, managing them, and summarizing them. In this stage, approaches like media management and communication management should be effectively used.

Recovery. It refers to follow-up summary and reconstruction efforts when the crisis occurred and was controlled effectively. It will provide experiences and supports for crisis management in the near future and effectively limit the recurrence of related crises, avoiding repeated mistakes made in the past.

The appropriate crisis management presented by Heath is the integration of four dimensions of $4 \mathrm{R}$ theory of crisis management, among which reduction crisis management is the core content. Since the reduction of risks, dilution and time saved enable decision-makers to reduce the probability of occurrence and loss caused by the crisis to the maximum extent. With the use of risk assessment, it could adopt appropriate and effective methods to supervise them so that crises could be prevented and avoided. And Heath also raised that reduction crisis management ran through the whole process of crisis management. In readiness crisis management, risk assessment in reduction will be used to find the deficiency of pre-warning system so that recovery and improvement efforts could be launched in time. In crisis management, reduction could also help the management identify the origin of crises and explore appropriate methods to address them. In recovery crisis management, the dimension of reduction could also evaluate the recovery schemes in effect and then find the risks coming with it so that a better rebound effect could be obtained in the recovery process.

\section{Research Methods}

There are mainly two study methods, namely, data collection and data reduction. 


\section{Data Collection}

It is quite common to use news data for research and analysis in the international academic community. Relevant news contents that Niederdeppe and his research team collected from the newspaper issued ranging from Apr. 22, 1994 to Dec. 31, 2001 in Florida, USA, a powerful and effective research method, turn out to understand circumstances of policy implementation and its effects as well as purposes of all parties (Niederdeppe, Farrelly, \& Wenter, 2007). An and Gower also concluded reports on US crisis in line with analyses on related news coverage and their contents (An \& Gower, 2009). And scholars in Mainland China also made analysis research based on data collection from news. Typical cases can be seen in the study on "The Death of Cuban Leader Fidel Castro" done by Ji Chenxiao whose contents are based on PhoenixNet and Xinhuanet $(\mathrm{Gi}, 2017)$. In view of the representativeness, neutrality, and pluralism of local newspapers in Macau, this study chose Macau Daily News, the official authoritative newspaper in Macau, as the data source. In terms of issue date, there are 40 pieces of news published in Macau Daily News from Aug. 22, 2017 to Sep. 30, 2017. Since Typhoon Hato landed in Macau on Aug. 23 officially, news coverage on it was mainly published from Aug. 24 to Sep. 2, 2017. After that, news coverage in relation to Typhoon Hato was getting less and less and even none till the end of September. Except on Sep. 6 and Sep. 20, Macau government set up Committee on Review of Major Disaster Response Mechanisms and Follow-up Improvement to release reports on typhoon to the public (Macau Daily News) and NRC (The National Disaster Reduction Commission) released "The Working Report of NRC Disaster Assessment Expert Group's Assistance to Macau in Typhoon Hato" (NRC, 2017) respectively. In addition, news reports on Typhoon Hato cannot be read on official website of Macau government after Sep. 10, thus literature review of this study is mainly from Macau Daily News.

\section{Data Reduction}

This study summed up all relevant news reports and data based on crisis stage theory management. Typhoon Hato officially landed in Macau on Aug. 23, Macau government set up Committee on Review of Major Disaster Response Mechanisms and Follow-up Improvement on Sep. 6 to release corresponding reports, and NRC released "The Working Report of NRC Disaster Assessment Expert Group's Assistance to Macau in Typhoon Hato". All these could be seen that the contents on the acute crisis stage and response crisis stage were repeated several times. With this in mind, this study defines dates of Typhoon Hato in three stages, namely, prodromal crisis stage, acute and response crisis stage, and recovery stage. And news is classified into response, mechanism discussion, and infrastructure so as to calculate its number to study the hot news, which can be seen in Table 1. Under this circumstance, a discussion based on 4R theory of crisis management will focus on analyzing the study result and proposed projects.

Table 1

Stages and Distribution of Relevant Time

\begin{tabular}{lccc}
\hline Date & $\begin{array}{l}\text { Prodromal crisis stage } \\
\text { (Aug. 22-23) }\end{array}$ & $\begin{array}{l}\text { Acute and response crisis stage } \\
\text { (Aug. 24-Sep. 5) }\end{array}$ & $\begin{array}{l}\text { Recovery stage } \\
\text { (Sep. 6-30) }\end{array}$ \\
\hline Reaction behavior & 2 & 9 & 4 \\
Mechanism discussion & 0 & 8 & 8 \\
Infrastructure & 0 & 2 & 7 \\
No. & 2 & 19 & 19 \\
Total & 40 & & \\
\hline
\end{tabular}




\section{Results}

In the part of literature review on Typhoon Hato mentioned above, it can be seen that its prodromal crisis stage focused on reaction behavior, while the acute and response crisis stage set store by response and mechanism discussion and recovery stage stressed on mechanism discussion and infrastructure. In the meantime, with crisis management stage theory as the core, $4 \mathrm{R}$ theory of crisis management will be used to study and analyze every crisis stage during the governance.

\section{The Analysis on Crisis Stage Theory}

Prodromal crisis stage. It mentioned in literature review that this stage is the pre-warning period of the occurrence of crisis, which focuses on reaction behavior. If crisis could be appreciated as early as possible, it will be easier to be dealt with. In fact, Macau's senators and relevant government departments all proposed and gave warnings. For instance, Macau's senators paid attention to measures of preventing floods whose effect were not good enough and Bureau of Maritime and Water of Macau called for merchants to prevent typhoons and floods. On the contrary, Meteorological Bureau of Macau which was supposed to play a role in prodromal crisis stage did not send clear warning sign and reacted quite slow, which indicated that readiness for warning was not enough (see Table 2).

Table 2

Reaction of Society and Government in Prodromal Crisis Stage

\begin{tabular}{|l|l|}
\hline Subject & Reaction \\
\hline Society & $\begin{array}{l}\text { Macau's senators noticed the ineffective measures of preventing floods and suggested setting up } \\
\text { inter-departments to prevent floods before Typhoon Hato landed. (Reduction: No reaction for the } \\
\text { suggestion on social affairs demonstrated the insufficient reduction of relevant departments of Macau } \\
\text { government when facing typhoon.) }\end{array}$ \\
\hline $\begin{array}{l}\text { Government } \\
\text { departments }\end{array}$ & $\begin{array}{l}\text { avoid suffering loss. (Readiness: Give pre-warning as suggestion and alert to prevent wind disasters.) } \\
\text { 2. Meteorological Bureau of Macau did not send clear warning sign and reacted quite slow. (Readiness: } \\
\text { No early warning for large disasters and slow response demonstrated that it had no enough readiness } \\
\text { when facing wind disasters.) }\end{array}$ \\
\hline
\end{tabular}

Acute and response crisis stage. It mentioned in literature review that this stage is the acute and response period of crisis management, which focuses on reaction behavior and mechanism discussion. In this stage, reaction force from the government and social affairs is crucial. Be it Chief Executive of Macau made remarks to all the Macanese, together with directors of some relevant departments made apologies, Director of Meteorological Bureau of Macau resigned, Macau government cited Garrison Law to request support from PLA (People's Liberation Army) Macau Garrison, or Macau government endeavored to restore electricity and water supply, Macau Foundation handled relief from the public, Macau's senators presented to value traditional virtues and released signal of criticizing the government and Macau government repaired the damaged public facilities, all these efforts are corresponding measures to address crisis causing great damage to Macau when it was exploded and spread quickly. Effective execution of measures in acute and response crisis stage is the key for Macau to having collective efforts to restore work and life so quickly. Moreover, Macau's senators also raised advice for different types of wind disasters, which can be reflected in response and recovery.

Recovery stage. It mentioned in literature review that this stage is the recovery period of crisis management, which focuses on mechanism discussion and infrastructure. To the greatest extent, Macau government and the public will make self-review and self-analysis to avoid the reoccurrence of the crisis, thus 
this stage may possibly introduce a new long-term effective response mechanism. Indeed, efforts like the establishment of Committee on Review of Major Disaster Response Mechanisms and Follow-up Improvement, the discussion and promise on improving the disaster prevention mechanism by Chief Executive of Macau and his officials with all sectors of society and technological support on water conservancy, power supply, telecommunication, and early warning from experts of NRC and Macau scholars, can be regarded as recovery, namely, the process of self-review and self-analysis. The resilience of Macau government in this stage will serve as an important evidence of the public to rebuild confidence for the government (see Tables $3 \& 4$ ).

Table 3

Response of Society and Government in Acute and Response Crisis Stage

\begin{tabular}{|c|c|}
\hline Subject & Response \\
\hline Society & $\begin{array}{l}\text { 1. Tap water crisis emergency solution in Macau was launched to solve the problem of water supply throughout } \\
\text { Macau. (Response: It endeavors to help the public restore normal life and stabilize social emotions.) } \\
\text { 2. Macau foundation and relevant departments handled relief from the public for wind disaster. (Response: It } \\
\text { aims to address the immediate physical and basic needs of the disaster-stricken people.) } \\
\text { 3. Macau's senators suggested that civil entities and volunteers should actively participate in the relief work and } \\
\text { attach importance to the traditional virtue of offering timely help to each other. (Response and recovery: General } \\
\text { public throughout Macau maintain traditional virtues to tide over difficulties with solidarity.) } \\
\text { 4. Macau government was criticized for no timely management and assistance. (Response and recovery: The } \\
\text { public criticized the government for no full preparation for working schemes and no timely assistance.) }\end{array}$ \\
\hline & $\begin{array}{l}\text { 1. Chief Executive of Macau made remarks to all Macanese through government office. (Response: This aims to } \\
\text { pacify the anxiety of the public to build a positive image of the government.) } \\
\text { 2. Macau government coordinated with Liaison Office of the Central People's Government in the Hong Kong } \\
\text { Special Administrative Region to prioritize the restoration of electricity throughout Macau. (Response: This } \\
\text { endeavors to restore the work and life of the public so as to reduce the economic loss to the minimum level.) } \\
\text { 3. Chief Executive of Macau led official directors of relevant departments in a flag-raising to apologize to the } \\
\text { public and lower to half-mast ceremony to remember the victims. Director of Meteorological Bureau of Macau } \\
\text { resigned. (Response: This aims to alleviate the dissatisfaction of the public and those responsible assume political } \\
\text { responsibility.) } \\
\text { 4. Macau government cited Garrison Law to request support from People's Liberation Army Macau Garrison for } \\
\text { the disaster relief work. (Response: This disaster relief effort with Chinese central government is the } \\
\text { government-to-government interaction under legislation.) } \\
\text { 5. Macao government repaired the damaged public facilities and revised relevant guidelines for damaged private } \\
\text { facilities. (Response and recovery: This aims to repair the damaged buildings and strengthen relevant guidelines } \\
\text { so as to avoid the occurrence of similar disastrous events.) }\end{array}$ \\
\hline
\end{tabular}

Table 4

The Response of Society and Government in the Recovery Stage

\begin{tabular}{|l|l|}
\hline Subject & Response \\
\hline Society & $\begin{array}{l}\text { Experts from NRC and Macau scholars provided technological support on water conservancy, power supply, } \\
\text { telecommunication, and early warning. (Recovery: This effort gained technological support from the central } \\
\text { government, social organizations, and academic circle so that the research on an effective response method on } \\
\text { crisis management could be investigated further.) }\end{array}$ \\
\hline $\begin{array}{l}\text { Government } \\
\text { departments }\end{array}$ & $\begin{array}{l}\text { Improf Executive of Macau set up Committee on Review of Major Disaster Response Mechanisms and Follow-up } \\
\text { and the inter-departmental coordination will be more efficient on disaster relief work.) } \\
\text { 2. Chief Executive and his officials together with all sectors of society discussed and promised to improve the } \\
\text { disaster prevention mechanism. (Recovery: This aims to set up and improve disaster prevention mechanism in a } \\
\text { bid to fulfill social responsibility and make self-review on the discussion together with the public to better } \\
\text { improve the disaster relief work.) }\end{array}$ \\
\hline
\end{tabular}

\section{An Analysis on 4R Theory of Crisis Management}

Although Macau government is still far from perfect in crisis management like dealing with Typhoon Hato 
(Macau Daily News), its endeavour to improve its governance on administrative reform cannot be denied. To improve its work, scholars from Mainland China gave suggestions as follows (Chan, 2008): (1) the engineering standard of disaster relief; (2) flood control and drainage facilities; (3) the protection of coastal wetlands; (4) the early warning and monitoring system; (5) the improvement of emergency schemes; (6) the enhancement of publicity and education; (7) the establishment of rescue teams; and (8) the use of scientific technology. All these suggestions on preventing and managing wind disasters should work with 4R theory of crisis management by all sectors of society especially by NRC on "The Working Report of NRC Disaster Assessment Expert Group's Assistance to Macau in Typhoon Hato" (NRC, 2017). Besides, the endeavour of the central government and Macau government to improve its governance in administrative reform should also work with these suggestions so that the governance of Macau could be further elevated and these suggestions could be implemented effectively.

Reduction. There are three pieces of advice for reduction.

(1) First, to explore and study flood control schemes. Macau government had submitted the research scheme on the resolve of flooding in Macau including its inner harbor and other low-lying areas (Macau Daily News) and received a response from relevant ministries and commissions of the central government, which supported the scheme in principle (Macau Daily News). Since some technological details need to discuss with the neighboring areas (NRC, 2017), Chief Executive of Macau will visit Guangdong Province to discuss and explore the technical details in flooding control of inner harbour (Macau Daily News) so that relevant schemes could be sped up to implement.

(2) Second, to absorb hydraulic engineering experiences in the national level. Macau presented two schemes in hydraulic engineering (Macau Daily News), one is to build tide gates and the other one is to build bunds. The former had been agreed to be implemented necessarily while the latter needs an in-depth argument with relevant schemes of the former (Macau Daily News). Meanwhile, relevant ministries and commissions recommended that Macau government entrusted mainland institutions and experts with rich experience and good capability to undertake the demonstration work in a bid to lift working efficiency and quality (NRC, 2017). And irrigationist sent by NRC also suggested establishing underground water storage system (Macau Daily News) and improve flood control project with high standards (Macau Daily News).

(3) Third, to improve the emergency response and coordination mechanism (NRC, 2017). Macau should improve Guangdong-Hong Kong-Macau emergency response and coordination mechanism and advance and synergize schemes on emergency plan, data information, relief supplies, resource allocation, and personnel training in the development of Guangdong-Hong Kong-Macau Greater Bay Area in an overall manner so as to improve the capability of coping with major disasters jointly (Macau Daily News).

Readiness. There are three pieces of advice for readiness.

(1) First, to establish and improve the preventive early warning and information mechanism. Macau government should establish and improve the early warning response mechanism and disaster report mechanism, improve pre-warning information service quality, and formulate pre-warning information response planning. For instance, Meteorological Bureau of Macau should strengthen targeted monitoring prediction of disastrous weather and send timely results to disaster resistance and relief leading organs (Macau Daily News). In addition, it should enhance the capability of emergency report and establish report system and statistic standard so as to improve its disposal capability and guarantee security in emergent cases (NRC, 2107). 
(2) Second, to make the best of resources in PLA Macau Garrison. With a small administrative region, although Macau is equipped with garrison and fire brigade, it still needs the defense of PLA Macau Garrison and it could not address major disasters by itself (NRC, 2017). Besides, national armed forces have always kept disaster prevention and relief training, thus they serve as important resources to address major disasters (Macau Daily News). In this context, Macau government should actively publicize the importance of national armed forces in disaster relief so that unnecessary misunderstanding could be avoided.

(3) Third, to sustain with scientific and technological data. Macau should strengthen technical application and scientific support. Advanced technologies like smart city, big data, cloud computing, Internet of Things, and artificial intelligence (Macau Daily News) could be well synergized public governance of Macau and turn its security management more smart, accurate, and efficient. With this in mind, the capability of basic data to operate the city should be also enhanced. And related database should be built to control the urban operation and provide data support for the assessment and analysis of public security and risk. In this way, basic data on public security and management could be integrated effectively and used rationally (NRC, 2017).

Response. There are three pieces of advice for response.

(1) First, disaster prevention and relief leading mechanism. Macau government should establish a disaster prevention and relief leading mechanism (Macau Daily News) directly led and commanded by Chief Executive of Macau, which can coordinate and unify the deployment of rescue and relief and rescue after disaster of every departments, thus the capability to safeguard public security and handle emergent cases could be enhanced. A sound and effective comprehensive disaster prevention and relief and emergency response management mechanism and emergency plans should be strengthened. And comprehensive risk assessment and the formulation of emergency plans on major disasters should be launched to effectively coordinate and unify civil entities for the rescue after disasters, which can give full play to social forces (NRC, 2107).

(2) Second, disaster prevention human resources management. Macau government should enhance its emergency decision-making and command ability by means of training and practices in a bid to analyze, decide, and master emergency better (Macau Daily News). Expert advisory team of emergency decision-making and command should be set up so that advanced theoretical techniques should be utilized to guide right decisions. Moreover, the specified quality of personnel should be also improved. The establishment of training bases, exchange visits and seminars can serve as good ways for professionals in the sectors like meteorology, fire-fighting, electricity power, hydraulic engineering, and telecommunication to better act in their areas (NRC, 2017).

(3) Third, social service and response for disasters. The targets of social service are mostly vulnerable groups, thus these groups are more likely to be reduced to difficulties when disasters occur. And their data information is collected by social service organizations. In this context, these organizations can provide practical assistance for those in need when their difficulties are identified in major disasters. With this in mind, Macau government should demand social service organizations to formulate social service disaster response mechanism (NRC, 2107) to share necessary data information so as to improve the precision of assistance. These efforts will be conducive to carry forward Macanese mutual help spirit and voluntary organizations for disaster relief could find those in greater need more effectively (Macau Daily News).

Recovery. Typhoon Hato not only caused a great loss to personal safety and financial security, but also reduced the confidence of Macanese and investors (Macau Daily News), thus recovery should be taken as a priority in crisis management (Macau Daily News). And there are three pieces of advice for recovery. 
(1) First, to formulate relevant laws and regulations and standards (Macau Daily News). Macau government should enhance the management laws and regulations on disaster prevention and pertinent standard system (NRC, 2017) and formulate related laws and regulations, such as emergency evacuation measures for major disasters (Macau Daily News) to clarify the rights and obligations of all subjects. Experiences from Mainland China could be learned to revise typhoon classification standards (Macau Daily News). Besides, studies should be done to enhance disaster prevention capability of buildings in Macau especially the public facilities (Macau Daily News). For instance, the construction requirements and disaster prevention standards of underground garage and building glass doors and windows should be reviewed (Macau Daily News) and emergency water and power supply design standards of buildings should be enhanced to better combat disasters (Macau Daily News).

(2) Second, to improve disaster prevention infrastructures. In view of disaster prevention infrastructures in Macau especially electricity supply overly dependent on national provider system (Macau Daily News), Macau government should establish a secure energy supply system that is diversified, complementary, and balanced. For instance, it should build a third pass in the national provider system throughout Macau, explore the operation schemes of isolated islands in major disasters (Macau Daily News), and boost the construction of local support power generation facilities as well as the capability of safety response and emergency water storage of water supply plants (Macau Daily News). All these efforts aim to improve the self-protection capability (NRC, 2107) so as to avoid the occurrence of water cut-off and blackout over large areas and fully protect the rights of city dwells in supervising the process of infrastructure construction (Macau Daily News).

(3) Third, to raise the quality of safety culture. Macau should strengthen the scientific promotion concerning public security to enhance the disaster prevention and resistance in communities and family. And it should also strengthen the team building of professional volunteers so that they will become more organized and professional to join in the emergency rescue orderly (NRC, 2017). Moreover, it can entrust social organizations to strengthen the publicity of rescue skills to strengthen the public awareness of unexpected development and the self and mutual medical aid (Macau Daily News).

\section{Discussion}

Taking Typhoon Hato as a case to make a monographic study on the branch of crisis management, it is found that implementation and development of urban renewal in crisis management is a paramount topic in this case. It can be concluded from the above that the study classifies the behavior of government and society into three stages, namely, prodromal crisis stage, acute and response crisis stage, and recovery stage; NRC had its advice on wind disasters with "The Working Report of NRC Disaster Assessment Expert Group's Assistance to Macau in Typhoon Hato" (NRC, 2017); 4R theory of crisis management and the enhanced governance for administrative reform of the central government and Macau give advice on the branch of crisis management, which can be seen in reduction (explore and study flood control schemes, absorb hydraulic engineering experiences in the national level, and improve the emergency response and coordination mechanism), readiness (establish and improve the preventive early warning and information mechanism, make the best of resources in PLA Macau Garrison, and sustain with scientific and technological data), response (disaster prevention and relief leading mechanism, disaster prevention human resources management, and social service and response for disasters), and recovery (formulate relevant laws and regulations and standards, improve disaster prevention infrastructures, and raise the quality of safety culture). Learning an important lesson from Typhoon Hato which 
exerted a severe impact on Macau, this study aims to promote national and Macau's administrative reform, which is also the further development of crisis management. In this way, the governance of Macau will be lifted and relevant advice on wind disaster could be implemented more efficiently.

The consequence of the case is that the incumbent Director of Meteorological and Geophysical Bureau of Macau resigned after the disaster for this department which should play a quite important role in the prodromal crisis stage with quite a slow response, and this is the only official who was requested to assume accountability. Afterwards, CCAC (Commission Against Corruption of Macau) had targeted investigation on this director's behavior during the landing of Typhoon Hato and found that his delinquency was associated with problems like internal management, personnel, and equipment management (CCAC, 2017). And this led to another punishment, which is no pension payment for four years (Macau Daily News). The assumption of political responsibility by someone responsible, to some extent, has pacified the discontent of the residents. However, although certain official had assumed corresponding obligation for the disaster, its severe impact still arouse the reflection and summary of government leaders and departments on the response to wind disasters. In the meantime, the aftermath "Administrative Obligation Accountability" makes "Principal Officials Accountability System" equally important in the daily works of government for Policy Address of Macau in the past few years has also mentioned the promotion of Principal Officials Accountability System through the third party assessment (Macau SAR, 2017), thus it is estimated that residents in Macau will have more demands on the systematic construction in this regard.

Indeed, old districts are the biggest victims in this disaster. Thanks to its vulnerability, such as the aging and disrepair problems of numerous public facilities, it could not strongly defend itself from the typhoon. In other words, it had no enough preparation in the prevention dimension. Therefore, the damage on old areas is more severe than others after the disaster. And repair tasks, such as the restoration of water and electricity supply, will be more important in the recovery stage (Macau SAR, 2017). It can be also seen in the acute and response crisis stage that a simple repair is not effective enough for old areas to combat the disaster and urban renewal will be another direction for old areas to set up a long-term settlement mechanism on wind disasters, thus Macau government stated the promotion of urban renewal in its 2018 Policy Address, including deepening work of Urban Renewal Commission to review pertinent tax policies, coordinate current laws, and implement mutual adaptation of urban renewal measures so as to accelerate the development of Macau's old areas (Macau SAR, 2017).

\section{References}

An, S. K., \& Gower, K. K. (2009). How do the news media frame crises? A content analysis of crisis news coverage. Public Relations Review, 35(2), 107-112.

Buchan, A. (1979). Crisis management, In C. Bell (Ed.), “Crisis Diplomacy” Stategic Though in the Nuclear Age. Baltmore, U.S.: Johns Hopkins.

CCAC (Commission Against Corruption of Macau). (2017). A survey on Meteorological Bureau's forecast procedure of typhoon and its internal management. Received from http://www.ccac.org.mo/cn/news/rpt20171019_cn.pdf

Chan, X. H. (2008). A study on the cause of typhoon in Xiamen and its strategies. China Water Resources.

De Sausmarez, N. (2004). Malaysia's response to the Asian financial crisis: Implications for tourism and sectoral crisis management. Journal of Travel \& Tourism Marketing, 15(4), 217-231.

Evans, N., \& Elphick, S. (2005). Models of management: An evaluation of their value for strategic planning in the international travel industry. International Journal of Tourism Research, 7(3), 135-150.

Fink, S. (1986). Crisis Management: Planning for the inevitable. New York: American Management Association. 
Fink, S. (1987). Crisis management. Taiwan: World Culture.

Gi, C. X. (2017). A study on the network news special report of unexpected events: A study case of special report of the death of Cuban leader Castro. New Media Studies, 14, 12-14.

Heath, R. (2001). Crisis management. Beijing: China Citic Press.

Huang, Y. D., \& Huang, Z. H. (2009). Storm Tide Case Study of Typhoon Hagupit in Hong Kong. Retrieved from http://www.weather.gov.hk/publica/reprint/r813.pdf

Jan, Z. Y. (2004). Crisis management: Theoretical structure. Linking Publishing.

Lee, Z. P. (2017). Macau, the backward village stripped prosperity by Typhoon Hato. Retrieved from https://theinitium.com/article/20170825-opinion-panlei-macau/

Macau Daily News. (2017a). A lesson from wind disaster prevention. Macau: Macau Daily News Press.

Macau Daily News. (2017b). Be preprared for the control of climate change risks. Macau: Macau Daily News Press.

Macau Daily News. (2017c). Chief Executive Leading Committee review disaster emergency mechanism would be followed and improved. Macau: Macau Daily News Press.

Macau Daily News. (2017d). Committee members suggested enhancing disaster relief on water and power supply. Macau: Macau Daily News Press.

Macau Daily News. (2017e). Emergency decision-making of officials must be improved. Macau: Macau Daily News Press.

Macau Daily News. (2017f). Experts suggested an integrated study on breakwater and tide gates. Macau: Macau Daily News Press.

Macau Daily News. (2017g). Experts suggested power cut in the wake of disaster prevention. Macau: Macau Daily News Press.

Macau Daily News. (2017h). Flood control and drainage planning of inner harbour had submitted to state council, Wanchai waterway tide gate planning will be submitted next year. Macau: Macau Daily News Press.

Macau Daily News. (2017i). Guangdong, Hong Kong and Macau worked together to synergize the lifeline. Macau: Macau Daily News Press.

Macau Daily News. (2017j). Human Resources and Social Security Bureau gave full assistance to restore service. Macau: Macau Daily News Press.

Macau Daily News. (2017k). Instructions released by Commission on Review Disasters. Macau: Macau Daily News Press.

Macau Daily News. (20171). Macau SAR requested to cite Garrison Law for the first time. Macau: Macau Daily News Press.

Macau Daily News. (2017m). Macau set up committee to review disaster emergency mechanism, organizations learned lessons and determined to improve relevant measures. Macau: Macau Daily News Press.

Macau Daily News. (2017n). Mr. Leimin strongly advocated to establish disaster warning mechanism. Macau: Macau Daily News Press.

Macau Daily News. (2017o). National Committee for Disaster Reduction called for disaster relief with six pieces of advice. Macau: Macau Daily News Press.

Macau Daily News. (2017p). Recalling a painful experience and reviewing disaster prevention. Macau: Macau Daily News Press. Macau Daily News. (2017q). Reports advocated enhancing emergency management laws and regulations. Macau: Macau Daily News Press.

Macau Daily News. (2017r). Review mechanisms on major disasters or evacuation. Macau: Macau Daily News Press.

Macau Daily News. (2017s). Secretary for Economy and Finance discussed emergency mechanism with business community. Macau: Macau Daily News Press.

Macau Daily News. (2017t). Setting up professional teams to study disasterous weather. Macau: Macau Daily News Press.

Macau Daily News. (2017u). Start with the construction of infrastructures to defend disasters. Macau: Macau Daily News Press.

Macau Daily News. (2017v). The construction of seawalls and waterlogging facilities should be strengthened for climate warming. Macau: Macau Daily News Press.

Macau Daily News. (2017w). The role of government in crisis management of natural disasters. Macau: Macau Daily News Press.

Macau Daily News. (2017x). To construct hydraulic engineering with high standards. Macau: Macau Daily News Press.

Macau Daily News. (2017y). To implement and strengthen disaster prevention infrastructure. Macau: Macau Daily News Press.

Macau Daily News. (2017z). To improve infrastructures. Macau: Macau Daily News Press.

Macau Daily News. (2017z1). Typhoon Hato highlighted the lack of Macau's response for infrastructure in emergency-scholars called for review of public facilities to improve disaster prevention mechanism. Macau: Macau Daily News Press.

Macau Daily News. (2018). Director of Meteorological Bureau of Macau resigned and was punished with no pension payment for four years. Macau: Macau Daily News Press. 
Macau SAR. (2017). 2018 Fiscal year policy address. Macau: Macau SAR.

Moynihan, D. P. (2009). The response to Hurricane Katrina. Geneva: International Risk Governance Council.

News Bureau of Macau SAR. (2017). All departments followed the resue after Typhoon Hato. Received from http://www.gcs.gov.mo/showNews.php?PageLang=C\&DataUcn=115838

Niederdeppe, J., Farrelly, M. C., \& Wenter, D. (2007). Media advocacy, tobacco control policy change and teen smoking in Florida. Tobacco Control, 16(1), 47-52.

NRC Disaster Assessment Expert Group's Assistance to Typhoon Hato in Macau. (2017). The working report of NRC disaster assessment expert group's assistance to Macau in Typhoon Hato. NRC.

Seeger, M. W., \& Ulmer, R. R. (2001). Virtuous response to organization crisis: Aaron Feuerstein and Milt Cole. Journal of Business Ethics, 31(4), 369-376.

WMO. (2018). 2017 Statement on the global climate. Retrieved from https://library.wmo.int/opac/doc_num.php?explnum_id=4520

Xue, L., Zhang, Q., \& Zhong, K. B. (2003). Crisis management: Challenges facing China in its transitional periods. China Soft Science, 4, 6-12.

Zhang, C. F. (2003). Public crisis management: A full integrated model and China's strategic choice. Chinese Public Administration, 217, 6-11.

Zhang, G. Q. (2003). Public crisis management and government obligation: A case study of SARS epidemic control. Management World, 12, 42-50.

Zhang, T. (2010). The exploration of crisis management theories. China's Foreign Trade, 19, 22-23.

Zhang, X. G., \& Zhao, H. G. (1992). The impact of El Nino on China's climate. China: China Meteorological News.

Zhang, Z. Y. (1992). The study on crisis and crisis management: An analysis of a study concept and theory. Journal of Police Science, 23(2), 137-158. 